\title{
Entertainment idols' art management innovation research
}

\author{
Zhang Yali", * \\ ${ }^{1}$ Department of Art and Design , 430070 Wuhan University of Technology, China \\ *email:614632341@qq.com
}

\begin{abstract}
This paper mainly expounds the entertainment idols' art management innovation , entertainment idols have been rising earlier in the West, and it has been rising in China from the $80 \mathrm{~s}$. With the development of media, entertainment idols have great influence on the way of public's life, behavior and values of the public. Art management originated in the Anglo American, and it has been rising in China in recent years. It becomes a new discipline. Entertainment idols' art management innovation play a great role in the development of entertainment idols.
\end{abstract}

Keywords: entertainment idols,art management,art management innovation.

\section{Introduction}

Nowadays, the influence of entertainment idols on is growing, their visual design and behavior often become the object for the public to imitate. Excellent idols will do positive influence to their works of art, so as to contribute to the cultural industry, effectively stimulating the growth of the national economy. They also play a great role in promoting cultural dissemination. Idols do a great influence to teenagers' values, such research summary of outstanding idol art management will help young people to set up correct life outlook and social values.

"Art management" is from the Anglo American, since the introduction of China in twenty-first Century, has gradually become a new discipline. Art management consists of three elements: Art Administration, art market and art law. In view of the entertainment idol art management, mainly includes the following several aspects: the Economic Corporation (broker), the art market, the economic contract.

\section{Current research situation in foreign countries}

Abroad for the study of entertainment idol culture, mainly concentrated in: hot phenomenon, the impact from the most popular groups, and the cultural trends set off by the entertainment idols.

In 2007, J. Amegashie in "American Idol: should it be a singing contest or a popularity contest?" .His analysis is related to the popular reality show "American Idol". It is pointed out that an idol has a good overall image, can make up for even cover the shortage.

In 2011, Saeyoung shin in "the study on fashion, beauty and design emotional image by external image type of Korean male idol stars". He putted forward the external image type and characteristic of Korean male idol, chose the famous group of 15 male idol image, analyzed the characteristics of the design of fashion and beauty. Again through the relevant expert seminar on classification, divided into six types: elite, stylish city, charm, rebellious children, sexy, and men's stunner. Come to the South Korean male idol image appeared, male and female temperament mixed images, showing a complex situation, and found constantly changing with the times.

In 2011, Hyunhee Cha in "Case Study on Korean Wave: focused on K-pop Concert by Korean idol group in Paris".He focused on the analysis of Korean success factors, changes in Korean and the future direction of development. The study also compares the performance of idol groups in Paris in June, as well as the views of South Korea and the French media. the causes included a variety of cultural elements: the fusion of oriental dance, Western popular, idol training system, and social media marketing activities.

In 2012, Kazumi Nagaike in "Johnny 's idols as Icons: female desires to Fantasize and Consume male idol / AFP / Getty Images" introduced popular Japanese male idol group Arashi, since his debut in 1999, in Japan has become today's most popular male idol group, 2009, in CD and DVD sales value 
reached 144 million yen ( $\$ 1$ billion 80 million U. S. dollars). Arashi won the most popular in Japan in 2010 show "Red Song war". Kazumi Nagaike pointed out that the "artist" or "broker" in the Japanese entertainment industry plays a leading force.

In 2012, Patrick W. galbraith in "Idols: the image of desire in Japanese consumer capitalism".He proposed the novel is part of an idol. The association of the real and imaginary images reveals how idols are made and how they are imagined.

2012, Shanguang Lv in "idols supply pattern in confident Reestablishment of national culture". He proposed the point that the information dissemination cost is very low in the information age.It provides a long-term moral education model for idols, namely the transition from traditional single mode of power to the power of the dominant and leading social combination mode. In the mode of power leading mode and other mode effect, the model of the idol supply, which meets the unprecedented challenge and the great disturbance of the social model of idol supply. To improve the idol's supply model from multi angle, so that we can rebuild the national cultural self-confidence.

\section{Current research situation in China}

The research on idol culture in our country starts late.

In 2005, He Xiaozhong in the "youth idol worship and education".He putted out that before the reform and opening up, there is no "Idol" in the title of the article,even the appearance of idols is the worship of religion.

In 2009, Peng Wenfeng raised in "the pioneer of romantic legend, in the culture of the United States cowboy image", due to the publicity and rendering of movies and novels, the American cowboy has become famous global literary idol image. They become the symbol of the United States of America with their diligence, courage, optimism, and pioneering spirit. Cowboy culture is not only an important part of American culture, but also a typical culture in the world culture. Although the cowboy era is very short, but the cowboy's literary image will always remain in the hearts of the people of the United States and the world.

In 2012, Zhang Beini in " the analysis of the overall personal image design ", proposed eight elements of the image design: shape factors, makeup elements, elements of hair, clothing styles elements, jewelry accessories factors, personality factors, psychological factors, cultural elements of self-cultivation.

In 2013, Yan Chen in "the modern visual communication design in the multi sensory expression" . She proposed multi sensory expression is the modern visual communication design of a new trend of development, is the inevitable product of the rapid development of science and technology of the times, science and technology, manufacturing processes and materials such as various influence and modern advanced design ideas and concepts embodied. Multi sensory expression for modern visual convey design presents a new visual language, into the modern visual communication design provides a broader design space, so that the design works is more infectious, powerful, persuasive , art, contemporary and scientific.

In 2014, Jun song ye put forward in "mass culture from the perspective of entertainment idols of subversion and Deconstruction", American Hollywood star to create a total of four steps: the first step:to create the image of the star; the second step :publicity; the third step: to determine the image of characters in movies; the fourth step: the idol play roles and acting propaganda. In addition, there are two kinds of the forms to control idols, first, the signing of the contract, the direct limit of its image packaging and work activities; second, Transform the image of an idol into a capital,then benefit from it.

In 2014, Xia Xuemin in the theory of personal image design principle of design aesthetics. She proposed personal image design is a integration of the plastic arts, visual arts, recombinant art. It contains the design aesthetics principles: the principle of individualization, system and whole principle, contrast and coordination principle, elastic and development principles. 
In 2015, Shi HuaZhong, Zou wei in "The analysis of the phenomenon and the evolution of the value of the "90" after the youth idol worship". They putted out that, in the 1980s, idols developed in the direction of diversification. The influence that idols for post-90s generation is the most significant. In 2015, Zhu Yige in "from AKB48 see Japanese idol culture". He proposed "Idol" is a word in Japanese definition refers only to popular artists, or active in multiple aspects of singer, actor, akira and so on. In addition, the Japanese media involved in the "Idol" only refers to the side of the singing and dancing of the group of young girls. He concluded that the Japanese idols' culture has become more and more civilian, it can be not perfect.

In 2015, Wang Min in "the phenomenon of the idol worship of Korean fans" He showed, as an example, the analysis of the characteristics of Korean fans idol worship, the formation mechanism and its cultural connotation. In the context of modern media, the idol worship of Korean fans is a kind of mass cultural consumption phenomenon, which is the final form of consumerism. The audience is not the specific consumer goods, but the symbol of the symbol and meaning. This consumption is not spontaneous, out of their own actual needs, but in the context of consumption is made out of.

\section{Conclusion}

To conclude, the role of brokerage firms or brokers in different countries of the idol art management has played a crucial role. The idols of different countries present their own works of art in different visual styles, which have different market, and these different markets have made important feedback to the art management. Moreover, the economic contract is an important tool to constrain the behavior of entertainment idols, but also an important prerequisite to limit its art market. Finally, only its art management to achieve continuous innovation, in order to better serve the public, for the public service.

\section{References}

[1] Wang, XJ. The Application of Modeling Materials In Personal Image Design [J]. Advanced Materials Research, 2011, (332-334):1615-1618.

[2] Kim, Heeyeon. Development of an Integrated Color Design System for Fashion Based on Personal Color Image [J]. Journal of the Korean Society of Costume, 2010, (60):61-73.

[3] Saeyoung, Shin . The Study on Fashion Beauty Design and Emotional Image by External Image Type of Korean Male Idol Stars [J]. Journal of Fashion Business, 2011, (15):71-84.

[4] Zena O'connor . Colour, contrast and gestalt theories of perception: The impact in contemporary visual communications design [J]. Color Res. Appl, 2015, (40):1.

[5] Lindy Ryan, Visual communication and literacy[M]. The Visual Imperative, 2016.

[6] Kang Zhang, Special Issue on Visual Information Communication - Theory and Practice[J]. Information sciences, 2015(30):424-426.

[7] Yu-An Huang, Chad Lin, Ian Phau, Idol attachment and human brand loyalty [J]. European Journal of Marketing, 2015(49):1234-1255.

[8] J. Atsu Amegashie, American Idol : should it be a singing contest or a popularity contest? [J]. Journal of Cultural Economics, 2009(33):265-267.

[9] Kazumi Nagaike, Johnny's Idols as Icons: Female Desires to Fantasize and Consume Male Idol Images [M]. Kazumi Nagaike in Idols and Celebrity in Japanese Media Culture, 2012.

[10] Hyunhee Cha, Case Study on Korean Wave: Focused on K-POP Concert by Korean Idol Group in Paris [M]. Kazumi Nagaike in Idols and Celebrity in Japanese Media Culture, 2011. 
[11] Shanguang Lv, Idols Supply Pattern in Confident Reestablishment of National Culture [M]. Information Computing and Applications, 2012.

[12] Patrick W. Galbraith, Idols: The Image of Desire in Japanese Consumer Capitalism [M]. Idols and Celebrity in Japanese Media Culture, 2012.

[13] Mu Yang. Research on the application and design of visual symbols [D]. Xi'an: Xi'an University of technology, 2009.

[14] Shi Huazhong. An analysis of the phenomenon and the evolution of the concept of "after 90" youth idol worship [J]. China Youth Research, 2015, (08): 79-81.

[15] Wang Min. An interpretation of the phenomenon of idol worship in Korean dramas: a case study of "from the stars" to the southeast, 2015,, (09): 82-84.

[16] Zhang Beini. Analysis of the overall image design of the individual [J]. North economic and trade, 2012, (03): 112-113. 